\title{
CONGENITAL ANOMALIES ASSOCIATED WITH CEREBRAL PALSY AND MENTAL RETARDATION
}

\author{
BY \\ RONALD S. ILLINGWORTH \\ From the Department of Child Health, the University of Sheffield and the Children's Hospital, Sheffield
}

(RECEIVED FOR PUBLICATION DECEMBER 15, 1958)

In the past 12 years 800 children with mental retardation or with cerebral palsy have been seen in the Children's Hospital, Sheffield, by the Department of Child Health. While looking through punch-card summaries of these cases, it became obvious that there was a much higher incidence of associated congenital anomalies in children with mental retardation without cerebral palsy than in those with cerebral palsy whether retarded or not. In view of the fact that in many ways there is a close similarity between the aetiological factors of the two conditions, it was felt that an analysis of the associated anomalies and their incidence in the two groups would be of interest. This paper analyses, therefore, the incidence and nature of associated congenital anomalies in the two groups of children.

\section{Method of Study}

The study is based on 300 children with cerebral palsy (excluding hydrocephalus), and 500 children with mental retardation without cerebral palsy. They are all consecutive cases, and constitute all the children seen with these conditions by the Department of Child Health in the past 12 years. They include all cases in which the diagnosis of mental retardation or of cerebral palsy was made and indexed, and therefore are not in any way selected. They include all degrees of severity, from the most trivial symptomless cerebral palsy and the most trivial degree of mental retardation, even including those children who are commonly considered to be in the normal range of intelligence (e.g. with an I.Q. of 90 or 95 ), to the most severely incapacitated idiots with a level of intelligence so low that it was unscorable. Many of those with a trivial degree of mental retardation formed part of another study on the predictive value of developmental tests in infancy (Illingworth, 1959). They may not necessarily be representative of mentally retarded children and those with cerebral palsy as a whole, but it is difficult to think of any reason why the series to be discussed should be significantly different from any larger series elsewhere.

For the purposes of the study, cases of pre-natal or natal origin have been separated from those of post-natal origin. Tables 1 and 2 show the aetiological factors in the two groups of children, as far as they could be ascertained. There were some children in whom the correct category was uncertain. The defect in the so-called acute infantile hemiplegia,

TABLE 1

AETIOLOGICAL TYPES OF CEREBRAL PALSY*

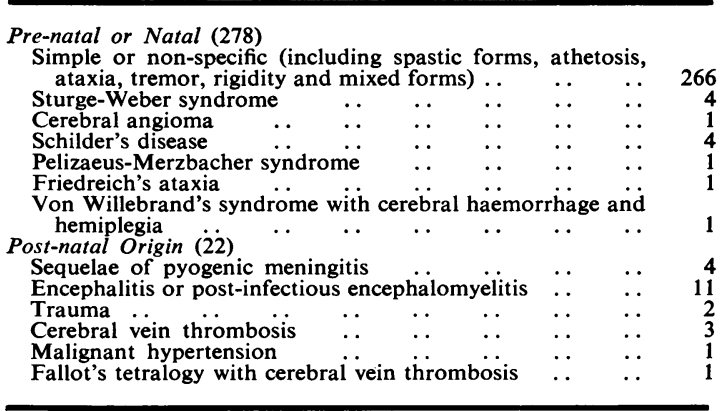

* Excluding hydrocephalus.

TABLE 2

AETIOLOGICAL TYPES OF MENTAL RETARDATION*

Pre-natal or Natal (465)

Mongolism without congenital cardiac lesion (some with

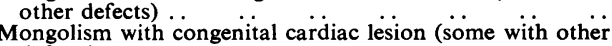

Mongolism with congenital cardiac lesion (some with other

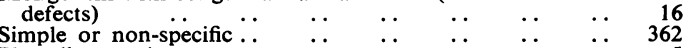

Phenylketonuria

Gargoylism

Tuberous sclerosis

Akinetic seizures with ${ }^{\circ}$ hypsarrhythmia developing in $\cdots$

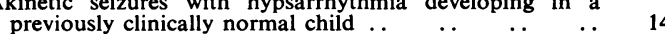

Post-natal Conditions (22)

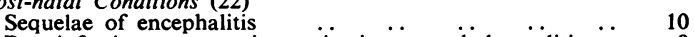

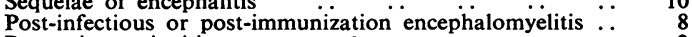

Pyogenic meningitis

Trauma.

Cerebral vein thrombosis

Uncertain Category (13)

Degenerative conditions of the brain (including two of Von

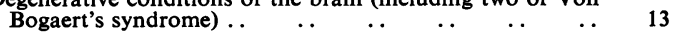


for instance, and in children who developed normally for five or six months and then suddenly deteriorated with a simultaneous development of akinetic seizures ('hypsarrhythmia') was thought likely to be of pre-natal origin. As it happens, none of these children in either group had any associated anomalies.

For the purposes of this study, I have included only those children in whom the defect was thought to be of pre-natal or natal origin. Mongolism being a separate entity, and the associated anomalies found in mongolism being well known, the 79 examples of this condition are not analysed separately, except only for the incidence of congenital heart lesions (16 in 79 children). This is, therefore, a study of 278 children with cerebral palsy and 386 children with mental retardation.

\section{Results}

The incidence of associated congenital anomalies in the 278 children with cerebral palsy is shown in Table 3. Defects of hearing and defects of vision, other than cataract, optic atrophy, choroidoretinitis and retrolental fibroplasia, have not been included. The list includes 19 children, one with a cleft palate, five with serious eye conditions, and one with congenital heart disease. Details of these children cannot be given here, because space will not permit.

In contrast to Table 3, Table 4 shows the incidence of associated anomalies in the 386 children

TABLE 3

CEREBRAL PALSY: ASSOCIATED CONDITIONS OR SYNDROMES IN PRE-NATAL OR NATAL FORMS (19)

Pièrre Robin syndrome with spina bifida, abnormal toes, congenital pyloric stenosis and spastic quadriplegia.. ..

Cataract, hepatosplenomegaly, spastic quadriplegia and con-

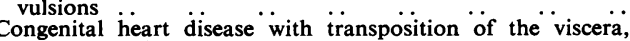

athetosis and convulsions ... Optic atrophy with syndactyly, mental deficiency and athetosis Optic atrophy (including two with convulsions)

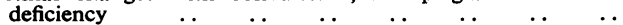

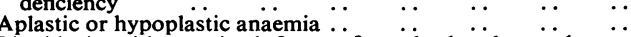

Lipoidosis with a mixed form of cerebral palsy and convulsions

Steatorrhoea with athetosis and mental deficiency $\quad \ldots \quad \ldots$

Precocious puberty with convulsions, mental deficiency and

$\underset{\text { Precocious puberty, }}{\text { hempastic quadriplegia, }} \ddot{\ldots}$ retrolental fibroplasia and convulsions ..

TABLE 4

MENTAL RETARDATION WITHOUT CEREBRAL PALSY, ASSOCIATED CONDITIONS OR SYNDROMES IN PRE-NATAL OR NATAL FORMS, EXCLUDING MONGOLISM

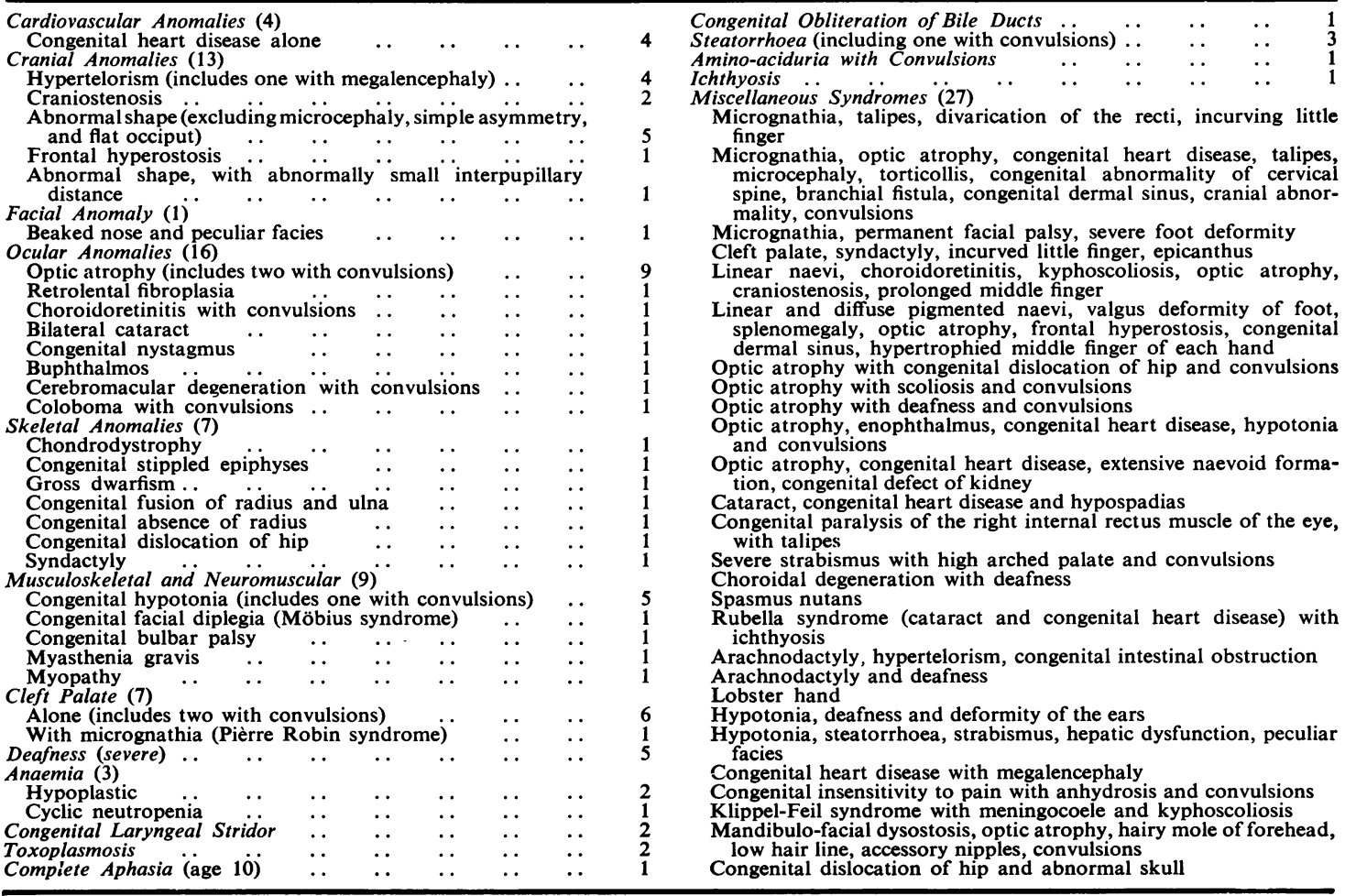


with mental retardation, giving details of those anomalies in 103 children. Minor defects, such as abnormalities of the ears, or minor degrees of strabismus, have been excluded. Deafness is only mentioned when it is severe. Cranial and facial anomalies have only been mentioned when they are very obvious. The list includes nine with congenital heart disease, 30 with serious eye lesions, and eight with cleft palate. The list concludes with 27 mixed syndromes of considerable interest which will not be further described here.

It will be seen that the incidence of associated congenital anomalies in children with cerebral palsy is 19 out of 278 children $(6.8 \%)$, and that in children with mental retardation is 103 out of 386 children $(26 \cdot 4 \%)$.

\section{Discussion}

Studies of the ante-natal history of mothers who have given birth to children with mental deficiency or cerebral palsy have shown that there are many features in common in the antecedents of these conditions. In both groups of conditions there is a greater incidence of antepartum haemorrhage, toxaemia, and other conditions leading to anoxia in the foetus, than is found in pregnancies leading to the delivery of a normal foetus (Lilienfeld and Parkhurst, 1951; Pasamanick and Lilienfeld, 1955; Lilienfeld and Pasamanick, 1955). Hence the observation that the incidence of associated anomalies is $6.8 \%$ in a group of 278 unselected children with cerebral palsy, as compared with one of $26.4 \%$ in 386 children with mental retardation, indicates, as one would expect, that there are other contributory factors, possibly largely genetic, which operate differently in the two groups.

It may be argued that the two groups are not strictly comparable in that while all the children in one group are mentally retarded, some of the children in the cerebral palsy group are not. It has already been explained, however, that children with only trivial degrees of mental retardation have been included in the former group, while it is known that only a small number of children with cerebral palsy have an I.Q. of over 100 (the figure given by Dunsdon (1952) being $8 \%$ ) while $50 \%$ have an I.Q.of less than 70 (Illingworth, 1958). Nevertheless, 16 of the 19 examples of associated anomalies occurred in children with cerebral palsy who had a low level of intelligence.

The high incidence of cleft palate and congenital heart disease in the mentally retarded group is of interest. It was shown elsewhere that the mean I.Q. of children with cleft palate is slightly lower than that of the normal population (Illingworth and Birch, 1956). Ireland, Witham and Harper (1955) found that the incidence of congenital heart disease in 723 mental defectives in institutions was $2 \cdot 35 \%$, while the incidence in the series of retarded children described above (excluding mongols) was 9 in 372 $(2.41 \%)$. Ireland et al. remarked that this incidence is seven times higher than that in the general population, and that even when mongols were excluded, the incidence was still several times higher than that in the general population.

\section{Summary}

The incidence of associated congenital anomalies in an unselected group of 278 children with cerebral palsy of pre-natal or natal origin is compared with that in 386 children with mental retardation of pre-natal or natal origin, excluding mongols.

The incidence of associated anomalies was $6.8 \%$ in the children with cerebral palsy and $26.4 \%$ in the children with mental retardation alone.

The high incidence of cleft palate and congenital heart disease in the mentally retarded group is noted.

The implications of these findings are discussed.

\section{REFERENCES}

Dunsdon, M. I. (1952). The Educability of Cerebral Palsied Children. Newnes Educational Publishing Co., London.

Illingworth, R. S. (1958). Recent Advances in Cerebral Palsy.

Churchill, London.
(1959). Arch. Dis. Childh. In the press.

and Birch, L. B. (1956). Arch. Dis. Childh., 31, 300

Ireland, C. R., Witham, A. C. and Harper, H. T. (1955). New Engl. J. Med., 252, 117.

Lilienfeld, A. M. and Parkhurst, E. (1951). Amer. J. Hyg., 53, 262. and Pasamanick, B. (1955). Amer. J. Obst. Gynec., 70, 93.

Pasamanick, B. and Lilienfeld, A. M. (1955). J. Amer. med. Ass., $159,155$. 